\title{
Effects of clonazepam and phenobarbital on the responding of pigeons maintained under a multiple fixed-ratio fixed-interval schedule of food delivery
}

\author{
ELBERT BLAKELY and LISA LEIBOLD \\ Western Michigan University, Kalamazoo, Michigan \\ MITCHELL PICKER \\ University of North Carolina, Chapel Hill, North Carolina \\ and \\ ALAN POLING \\ Western Michigan University, Kalamazoo, Michigan
}

\begin{abstract}
The effects of clonazepam $(0.25-4.0 \mathrm{mg} / \mathrm{kg})$ and phenobarbital $(10-80 \mathrm{mg} / \mathrm{kg})$ were examined in pigeons responding under a multiple fixed-ratio 50 fixed-interval 90 -sec schedule of food delivery. When given acutely $30 \mathrm{~min}$ prior to testing, the lowest dose of each drug generally increased responding under both components of the multiple schedule, whereas high doses decreased responding. Time-course determinations revealed maximum rate-reducing effects when phenobarbital was given $30 \mathrm{~min}$ prior to testing; 15 - and 30 -min presession intervals were similarly effective with clonazepam. When a 120-min presession interval was used, responding generally exceeded control rates for clonazepam, but not for phenobarbital.
\end{abstract}

If one accepts a prevalence of $0.3 \%$ to $0.6 \%$ (Hauser, 1978 ), roughly 750,000 to $1,500,00$ individuals suffer from epilepsy in the United States alone. Their treatment, in all likelihood, will involve prolonged exposure to one or more of the 17 antiepilepsy medications currently marketed (Swinyard, 1982). Although anticonvulsants are widely and effectively used in the treatment of epilepsy in its various forms, the behavioral side effects of such medications are poorly understood (Gibbs et al., 1982). Clinical investigations have not revealed the precise behavioral effects of such drugs, but they have provided evidence that anticonvulsants can deleteriously affect behavior. Recent research with nonhumans (summarized by Poling \& Picker, in press) has compared the effects of antiepilepsy medications under a number of operant conditioning procedures. Findings provide a crude profile of the behavioral actions of several anticonvulsants, but detailed understanding of the behavioral actions of these agents necessitates further investigation. In an attempt to explore further the effects of anticonvulsants in nonhumans, the present study examined the effects of clonazepam and phenobarbital on the responding of pigeons main-

This research was supported by National Institutes of Health Grant No.1 R01 NS 20216-01. The authors wish to thank Scott Wallace for the excellent technical assistance he provided. Address correspondence to: E. Blakely, Department of Psychology, Western Michigan University, Kalamazoo, MI 49008. tained under a multiple fixed-ratio 50 fixed-interval $90 \mathrm{sec}$ (mult FR 50 FI 90-sec) schedule of food delivery. Although these drugs similarly increase errors in pigeons performing under repeated acquisition and delayedmatching-to-sample procedures (Picker \& Poling, 1984; Picker, White, \& Poling, 1985), their effects on schedulecontrolled responding have not been compared directly. Because clonazepam is a benzodiazepine and phenobarbital a barbiturate, and because the clinical applications of the two drugs differ, determining the range of conditions under which they produce similar behavioral effects may be of some interest.

\section{METHOD}

\section{Subjects and Apparatus}

Six experimentally-naive barren hen White Carneaux pigeons, maintained at $80 \%$ of free-feeding weights, served as subjects. The birds were individually housed with unlimited access to water and grit in a constantly illuminated room.

Subjects were tested in three computer-controlled operant conditioning chambers, described in detail by Picker and Poling (1984). Each chamber contained a food hopper and three response keys; only the center key was operative in the present study.

\section{Procedure}

After initial keypeck training, subjects were exposed to a mult FR 50 FI 90 -sec schedule of food delivery. Under this schedule, the color of key illumination alternated at 5-min intervals. When the key was lighted in red, a FR 50 schedule was in effect, whereas a FI 90 -sec schedule was in effect when the key was lighted in blue. A 3-sec delivery of mixed 
grain followed every 50th keypeck under the FR 50 schedule. Under the FI 90-sec schedule, a 3-sec food delivery followed the first response emitted at least $90 \mathrm{sec}$ from the previous food delivery, or from the onset of blue-key illumination. Sessions were $30 \mathrm{~min}$ in duration and always began with blue-key illumination (i.e., with the FI 90 -sec schedule). Sessions were conducted 6 days per week, at about the same time each day.

When all subjects evidenced stable response rates (i.e., no visually evident trend over 10 consecutive sessions) under both components of the multiple schedule, they were divided into two groups of 3 . One group received clonazepam, the other phenobarbital. Five doses of clonazepam $(0.25,0.5,1,2$, and $4 \mathrm{mg} / \mathrm{kg}$, expressed as a salt) and five doses of phenobarbital $(10,20,40,60$, and $80 \mathrm{mg} / \mathrm{kg}$, expressed as a base), selected on the basis of previous findings from our laboratory (e.g., Picker \& Poling, 1984), were examined. Each drug dose was given to 3 subjects on a single occasion. Doses were administered in an irregular order, and active drug was given only when responding appeared stable across three consecutive control sessions, at least one of which was preceded by an injection of the vehicle used with the drug being evaluated (see below). All injections were given intramuscularly $30 \mathrm{~min}$ prior to experimental sessions, at a volume of $1 \mathrm{ml} / \mathrm{kg}$. Clonazepam (Hoffmann-La Roche, Nutley, NJ) was dissolved in a solution consist- ing of 4 parts propylene glycol, 1 part ethyl alcohol, and 5 parts distilled water, and then was diluted with distilled water to the desired injection volume. Phenobarbital (Sigma Chemical Co., St. Louis, MO) was dissolved in distilled water with sufficient sodium hydroxide added to neutralize the drug to the sodium salt.

After initial dose-response determinations, the effects of presession injection interval were evaluated. In this evaluation, subjects received a single dose of clonazepam or phenobarbital at presession injection intervals of 15,60 , and $120 \mathrm{~min}$. The dose administered to an individual bird was the lowest one that reduced FR responding by at least $50 \%$ during initial dose-response testing.

\section{RESULTS AND DISCUSSION}

Figures 1 and 2 depict the effects of acute administrations of clonazepam and phenobarbital, respectively. When drugs were administered $30 \mathrm{~min}$ prior to the session, dose-response curves were similar for both drugs and component schedules. At the lowest dose administered, clonazepam and phenobarbital generally in-

\section{FIXED-RATIO}

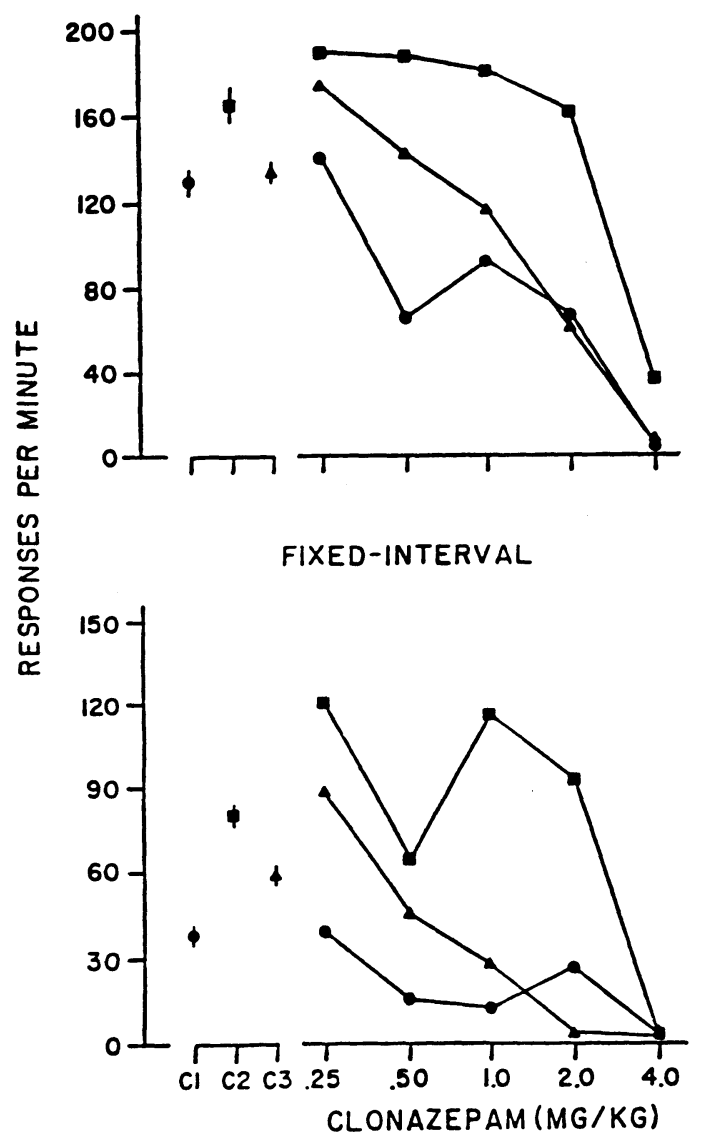

\section{FIXED-RATIO}

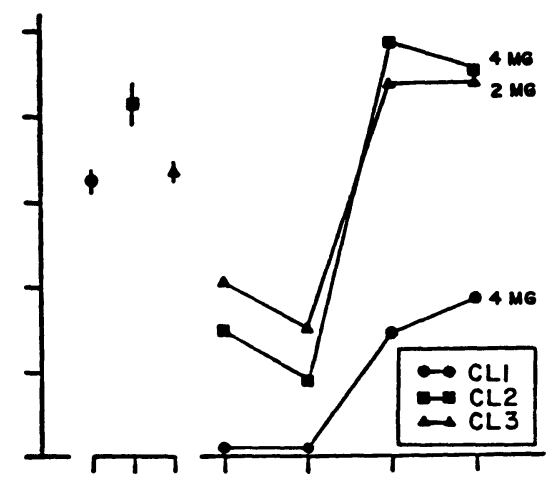

FIXED-INTERVAL

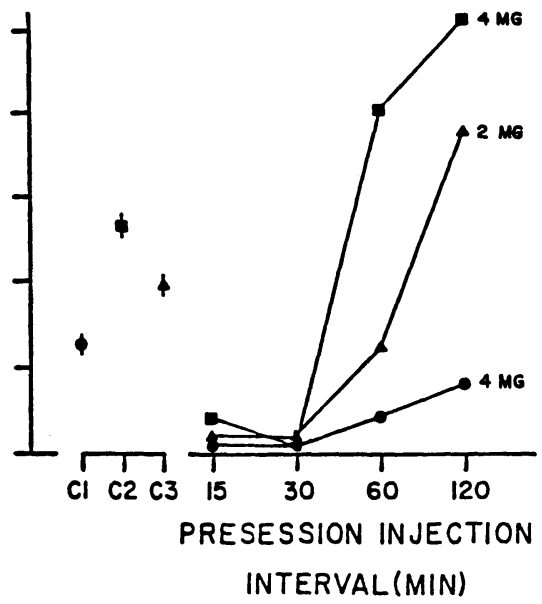

Figure 1. Effects of acute administrations of clonazepam on the response rates of individual pigeons responding under a mult FR 50 FI 90-sec schedule of food delivery. Panels on the left show rates of responding when the drug was administered im $\mathbf{3 0}$ min prior to behavioral testing; effects of varying the presession injection interval are shown in the right panels. The dose given to each subject (indicated in the figure) during the time-course determination reduced rate of responding under the FR component by a minimum of $50 \%$ when administered 30 min prior to testing. Control data are expressed as the mean response rate for the three sessions immediately prior to all drug administrations; vertical lines indicate the standard error of the mean. 
FIXED-RATIO
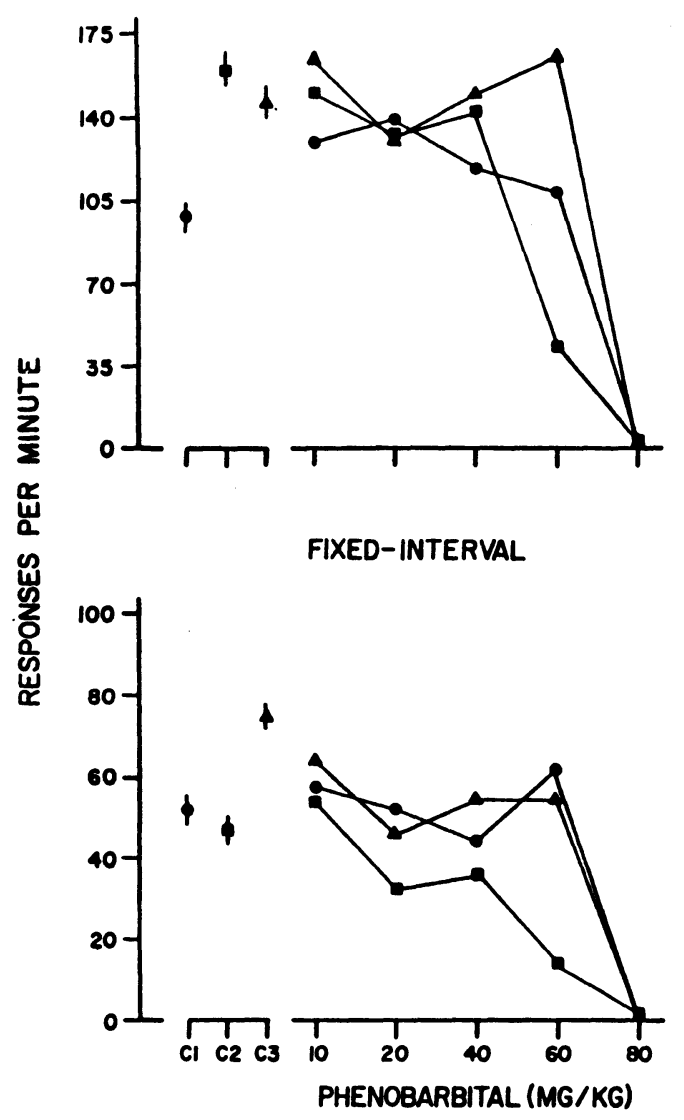

FIXED-RATIO

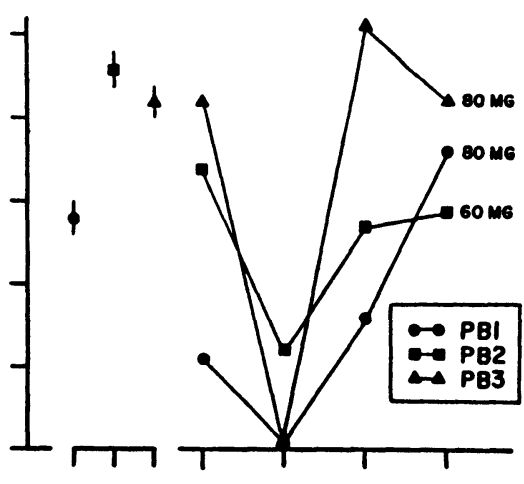

FIXED-INTERVAL

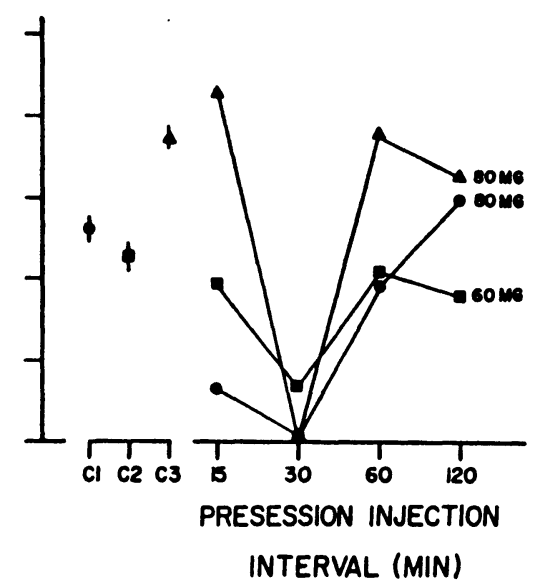

Figure 2. Effects of acute administrations of phenobarbital on the response rates of individual pigeons responding under a mult FR 50 FI 90-sec schedule of food delivery. Details are as in Figure 1.

creased responding under both the FR and FI components. High doses of each drug produced dose-dependent decreases in responding. The largest rate-decreasing effects of clonazepam were observed at the 15- and 30-min presession injection intervals. At the $120-$ min presession injection interval, drug-induced rate increases were observed in 2 of 3 subjects exposed to clonazepam; this effect was most evident in the FI component. Phenobarbital produced maximal suppression of responding at the 30-min presession injection interval. In most instances, response rates were within the control range when this drug was given $120 \mathrm{~min}$ prior to the session.

Studies of drug effects on schedule-controlled responding have long played an important role in behavioral pharmacology. Such studies have yielded important information about general drug-behavior interactions, as well as about the behavioral actions of specific drugs and drug classes (see McKearney \& Barrett, 1978). Previous investigations have demonstrated that relatively high doses of phenobarbital reduce response rates of rats under FR schedules of food delivery (Commissaris, Lyness, Moore, \& Rech, 1981; Picker, Thomas, Koch, \& Poling, 1985) and the response rates of mice under random-interval schedules of food delivery (Middaugh, Blackwell, Bog- gan, \& Zemp, 1981). The present results, obtained with pigeons, are generally in agreement with these prior findings. These data provide no evidence of rate-dependent effects for phenobarbital, although pentobarbital, another barbiturate, is known to produce such effects under some conditions (e.g., Dews, 1955).

Although the behavioral effects of clonazepam have received relatively little experimental attention, the actions of other benzodiazepines (chlordiazepoxide, diazepam) on schedule-controlled behavior have been explored in considerable depth (see Dantzer, 1977; Sanger \& Blackman, 1981). According to Sanger and Blackman (1981), "chlordiazepoxide, and probably other benzodiazepines as well, do not exert effects that can be consistently described as rate-dependent, but this is not to say that under some circumstances control rates of responding may not have some role to play in determining the effects of these drugs" (p. 18). There was no evidence of ratedependent effects for clonazepam in the present study.

\section{REFERENCES}

Commissaris, R. L., Lyness, W. H., MoORe, K. E., \& ReCh, R. H. (1981). Central 5-hydroxytryptamine and the effects of hallucinogens 
and phenobarbital on operant responding in rats. Pharmacology, Biochemistry \& Behavior, 14, 595-601.

DANTZER, R. (1977). Behavioral effects of benzodiazepines: A review. Biobehavioral Review, 1, 71-86.

DEws, P. B. (1955). Studies on behavior: I. Differential sensitivity to pentobarbital of pecking performance in pigeons depending on schedule of reward. Journal of Pharmacology \& Experimental Therapeutics, 115, 343-401.

Gibbs, E. L., Gibbs, T. J., Gibbs, F. A., Gibbs, E. A., Dikmen, S., \& HermanN, B. P. (1982). Antiepilepsy drugs. In S. E. Breuning \& A. Poling (Eds.), Drugs and mental retardation (pp. 268-329). Springfield, IL: Thomas.

HAUSER, W. A. (1978). Epidemiology of epilepsy. Advances in Neurology, 19, 313-339.

McKearney, J. W., \& BARRETt, J. E. (1978). Schedule-controlled behavior and the effects of drugs. In D. E. Blackman \& D. J. Sanger (Eds.), Contemporary research in behavioral pharmacology (pp. 168). New York: Plenum Press.

Middaugh, L. D., Blackwell, L. A., Boggan, W. O., \& Zemp, J. W. (1981). Brain concentration of phenobarbital and behavioral activation or depression. Pharmacology, Biochemistry \& Behavior, 15, 723-728.

Picker, M., \& Poling, A. (1984). Effects of anticonvulsants on learning: Performance of pigeons under a repeated acquisition procedure when exposed to phenobarbital, clonazepam, valproic acid, ethosuximide, and phenytoin. Journal of Pharmacology \& Experimental Therapeutics, 230, 307-316.

Picker, M., Thomas, J., КосH, C., \& Poling, A. (1985). Effects of phenytoin, phenobarbital, and valproic acid, alone and in selected combinations, on the schedule-controlled behavior of rats. Pharmacology, Biochemistry \& Behavior, 22, 389-393.

Picker, M., White, W., \& Poling, A. (1985). Effects of phenobarbital, clonazepam, valproic acid, ethosuximide, and phenytoin on the delayed-matching-to-sample performance of pigeons. Psychopharmacology, 86, 494-498.

Poling, A., \& Picker, M. (in press). Behavioral effects of anticonvulsant drugs. In T. Thompson, P. B. Dews, \& J. E. Barrett (Eds.), Advances in behavioral pharmacology (Vol. 5). Greenwich, CT: JAI Press.

SANGer, D. J., \& Blackman, D. E. (1981). Rate-dependence and the effects of benzodiazepines. In Advances in behavioral pharmacology (Vol. 3, pp. 1-20). New York: Academic Press.

SwINYARD, E. A. (1982). Introduction. In D. M. Woodbury, J. K. Penry, \& C. E. Pippenger (Eds.), Antiepileptic drugs (pp. 1-10). New York: Raven Press.

(Manuscript received for publication January 20, 1986.) 